\title{
Strategy of energy efficiency enhancement for sustainable and environmentally balanced development of gold deposits at its final stage
}

\author{
Marina Ryl'nikova ${ }^{1 *}$ \\ ${ }^{1}$ IPKON RAS, 111020 Moscow, Russia
}

\begin{abstract}
The article presents the rationale of the concept and defines the principles of keeping the production potential of a mining engineering system at the final stage of development to prevent a mine closure accompanied by a range of social, economic and environmental problems resulting from the disturbance of habitat, as well as lithosphere and hydrosphere parameters, etc. This concept can be implemented due to radically new geotechnology solutions aimed at the alteration of gold ore mining and processing technologies with the eventual disposal of wastes to mined-out areas. At the current stage of mining science advancement, energy efficiency and resource saving are inseparably connected with the sustainable use and conservation of non-renewable natural energy sources and transition to the use of technology-related energy sources regenerated in the course of mining. In this case, energy efficiency is viewed as economically feasible electricity consumption achieved at the current level of mining machinery and technology development and mandatory compliance with environmental safety requirements. Enhancement of energy efficiency envisages the minimization of energy consumption for mining processes while maintaining the scale of production and tackling the accompanying non-production challenges.
\end{abstract}

For the first time, for gold deposit conditions the author proposes general methodological approaches, in combination with a certain level of details, to the problem of systematization and estimation of opportunities of renewable energy sources use in the course of implementation of mining processes. The importance of the mentioned problem solution for mining sciences is in finding the evidence of the fact that in the course of implementation of mining processes within the framework of a mine various technology-related renewable energy sources are formed, which were not taken into account earlier, while the discovered objective laws of the formation of these energy sources, which, depending on the design and technology parameters of mining operations, provide a choice of preferable technological solutions to minimize the consumption of external energy supply by a mine. Development of new technical and technological solutions on the conversion of technology-related energy sources into electricity, its accumulation and consumption for in-mine needs will significantly minimize the consumption of external power supply, and in general it will enhance energy efficiency of mining operations and involve deposits located in remote and hard-to-reach areas in production.

\section{Introduction}

In the latest decades the problem of mining energy efficiency enhancement and resource saving, along with the issues of mine technical modernization and innovative technological development are viewed as top priorities [1-4].

In some countries and regions with a well-developed mining sector mines consume $10-55 \%$ of the total electricity generation. For instance, in SAR the share of mines accounts for $6 \%$, in Brazil - for $4 \%$, in Colorado for $18 \%$, in the USA - for $3 \%$ as an average, in Germany - for $46 \%$, while in Russia - for 55\% [5]. Moreover, in the pattern of energy consumption in Russia the share of mineral mining and processing industry prevails (Fig. 1).

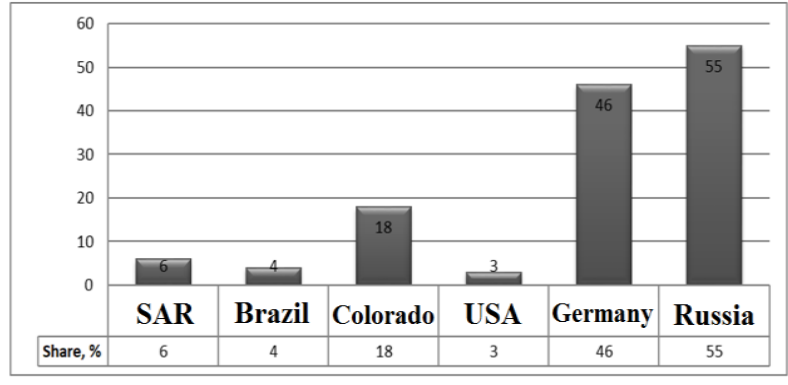

Fig. 1.1 Share of mining sectors in the total electricity consumption by country

It is important to note that the natural growth of mining depth results in the increase of energy consumption. It is often the case, when electricity demand of a large mine is higher than that of the municipal infrastructure providing services to it. Therefore, in case of continuous current trends there will 
inevitably come a moment, when energy costs of mineral mining at many Russian deposits in terms of energy source global prices will be comparable with the recoverable value of mined minerals.

In this context, in the latest years in particular, the global mining science and practice attach special attention to the substantiation of methodological and engineering solutions providing the enhancement of mining energy efficiency [6-8].

Energy efficiency is viewed as economically feasible electricity consumption achieved at the current level of mining machinery and technology development and mandatory compliance with environmental safety requirements. Enhancement of energy efficiency envisages the minimization of energy consumption for mining processes while maintaining the scale of production and tackling the accompanying nonproduction challenges.

At the current stage of mining science advancement, energy efficiency and resource saving are inseparably connected with the sustainable use and conservation of non-renewable natural energy sources and transition to the use of technology-related energy sources regenerated in the course of mining operations. These particular solutions form the philosophy of the full environmentally balanced cycle of comprehensive development of mineral deposits and of the transition period for the formation of Industry 4.0 innovation wave of a mine.

Long-term benefits of the research into the use of renewable energy sources are determined by the fact that their creation and application on the basis of innovative process flow sheets of energy saving and energy regeneration in mine planning both "from scratch", and in the course of modernization and reconstruction provide the enhancement of mine operation energy efficiency within the shortest possible period. For this purpose the operation of each mineral deposit site under development must envisage an opportunity of energy cost increase compensation in case of depletion of reserves of high- and medium-grade ore, deterioration of run-of-mine ore quality, strengthening of product quality requirements, particularly in conditions of growing mining depth.

\section{Basic approach to the rationale of gold deposit development at the final stage}

Application of modern energy saving and energy regeneration systems is rather important for operating gold mines run by Yuzhuralzoloto Group of Companies (YuGK AO) specializing in gold ore mining and saleable gold production at refineries.

Development of vein gold deposits of the South Ural by YuGK AO is currently characterized by a significant decrease of their resource portfolio reproduction, deterioration of quality characteristics of mined ore, more and more unfavorable geomechanical conditions, increasing production costs [9]. Most deposits are currently at the final stage of the development process, i.e., at the stage of finalizing the development of onbalance (economically mineable) reserves in accordance with the baseline plan. A mining company with ever increasing frequency has to bring into development the sites of a deposit with unfavorable conditions, low and rather variable gold ore grades and to transfer mining to deeper horizons, where "conventional" technologies" become less economically feasible, and entailing risks associated with rock bumps or even loss-making that predetermines significant operation costs.

In the above described conditions it is very important to enhance productivity of ore underground mining due to the most efficient use of the total resource potential of deposits, namely: standard- and low-grade ores, associated minerals, middlings, technology-related formations of the previous years, mineralized water, underground space, as well as already disposed and current ore mining and processing wastes, with the concurrent reduction of saleable production costs and improvement of industrial and environmental safety of production [10].

Generalization of gold deposit development practice has made possible the grounding of the concept and defining of the principles of keeping the production potential of a mining engineering system at the final stage of development to prevent a mine closure accompanied by a range of social, economic and environmental problems resulting from the disturbance of habitat, as well as lithosphere and hydrosphere parameters, etc. This concept can be implemented due to radically new geotechnology solutions aimed at the alteration of gold ore mining and processing technologies with the eventual disposal of wastes to mined-out areas.

The main subject-matter of the concept comes down to an idea that at the final stage of deposit development the complete unlocking of mine reserves and resources potential and provision of sustainable development are inseparably tied with comprehensive multipurpose use of all kinds of georesources, which can be efficiently brought into development on a particular site of lithosphere in the period of deposit development specified by the plan. Opportunity of phased use of georesources is based on the properties of the Earth underground resources - their multifaceted nature, multifunctionality and non-depletability. It is these particular properties of underground resources that determine the fact that the final stage of mine evolution can and preferably must become a stage of stepwise evolution rather than its closure, and at every stage envisage the involvement of a new kind of georesources in advantageous and efficient use in an arbitrary indefinitely long period.

To provide the conditions for mine evolution at the final stage of development it is possible and desirable to perform the restructuring of georesources in the course of reforming, reorganizing and technical upgrading of production. In this case, it is possible to create new kinds of underground resources or convert the potential resources to actual ones due to the application of resource reproduction technologies $[11,12]$. 
Along with the issues of technical modernization of mining YuGK AO currently deals with a problem of energy efficiency enhancement as a top priority at stages of mineral mining, processing and metallurgical extraction. This problem can be solved by way of energy sources consumption cutting and more efficient use of natural energy sources, explosives, fuel and gas, cancellation of centralized electricity supply and transition to in-mine power generation that provide nearly two-fold cutting of energy costs in the structure of ore production costs [10]. The problem solution acquires even greater importance, as most gold deposits are located in the regions, where local power supply sources are not available.

\section{Evolution of energy regenerating geotechnologies}

The growth of energy efficiency of ore mining at deep horizons of deposits is based on the search for and advantageous use of electricity regenerated in mining processes due to technology-related renewable energy sources for in-mine energy consumption.

Studies performed by IPKON RAS researchers have proved the idea that implementation of geotechnology processes in the course of technology-related transformation of underground resources there exists a real opportunity of compensation of some portion of energy consumed in the process of mining. It is realizable by way of energy regeneration due to energy sources formed in geotechnology processes, such as, water drainage, ventilation, backfilling of mined-out areas, ore drawing, transportation (recuperation of energy of downhill movement of transport machinery and vessels), downward force of heavy machinery, use of energy of rock pressure, natural and induced rock mass motion [13-15]. These sources are not obvious outside a mining engineering system, and can be reproduced and converted in electricity only in technology-related transformation of underground resources. The principal condition determining the materializing of the above listed kinds of regenerated energy is a typical feature of ore deposit mining, namely the difference in elevations of horizons, at which mineral is mined. It is important to note that in the earlier years, the world practice did not take into account these resources even in the pattern of the known renewable energy sources.

For instance, in the process of ore mining and processing within the boundaries of mining and processing enterprises the multi-million volumes of runof-mine material, fluids and slurry are transferred. They have energy, which is equivalent to dozens of MW.h per year. For example, a backfilling mixture pumped from the surface of Gubkin Mine (KMA) to mined-out areas to a depth of $250 \mathrm{~m}$ at a rate of 4.5 million $\mathrm{t} / \mathrm{year}$ has potential energy, which is equivalent to 2.5 million $\mathrm{kW} . \mathrm{h}$ [13].

Research into opportunities of generation, collection and storage of electricity from renewable energy sources of natural and technology-related origin performed in cooperation with the special division of the Laboratory for Environmentally Balanced Mineral Deposit Development located in the town of Plast and Yuzhuralzoloto Group of Companies has shown that in conditions of underground mines of the Urals developing steeply dipping vein gold ore bodies at great depths of Kochkarskoe, Svetlinskoe, Berezovskoe and Novotroitskoe deposits the greatest energy potential belongs to the formed in mines and moving downward gravity flows of hydraulic mixture circulating on a yearround basis. These mixtures are contaminated waters containing high concentrations of solids within a water drainage system, as well as consolidated and hydraulic backfilling mixtures formed on the basis of ore mining and processing wastes. These flows are formed at horizons collecting surface and ground waters, as well as in surface backfilling systems, ore processing plants, tailing storage facilities, and they move predominantly by gravity downward to main horizons of water drainage or zones of backfilling operations of underground mines [14].

Energy potential of these flows is rather high. As it has been proved by the performed calculations, the collection and conversion of hydraulic flow energy to electricity is able to make good up to $40-50 \%$ of energy consumed by underground mines.

In the course of research, the main parameters of geotechnology of electricity regeneration within the framework of the mining and engineering system incorporating small-capacity hydropower plants (HPP) (up to $100 \mathrm{~kW}$ ) have been designed with due account for the actual mining depth at underground mines and specified values of level and sublevel height: intermediate - from $10 \mathrm{~m}$ and more, sublevel - at least $15 \mathrm{~m}$, and level - within 30-60 m [15].

For the materialization of the energy potential of hydraulic mixture flows in the course of pilot run of the novel technology of mine flow energy regeneration some HPP operational models with small-capacity electricity generators having different types of blades and wheels have been designed. Estimates have been made of the efficiency, conditions of operation and performance of hydro turbines for the conversion of energy of falling downward hydraulic mixtures varying in composition, viscosity and density depending on the head pressure and angle of feeding to the turbine, its location in a mining engineering system have been found.

Historic analysis of the world hydropower achievements and comparison of design varieties of hydro turbines used both in distributed power generation, and in modern dam hydropower plants of extra high capacity have revealed the main trends of hydro turbine design development, made possible the selection of the best type of bucket-, rotor- and axial-type hydro turbine design, which is most suitable for underground mine conditions of energy regeneration with the use of small capacity HPP (up to $100 \mathrm{~kW}$ ), as well as the right choice of the receiving nozzle design with due account for the feeding direction and material composition of mixtures, as well as the development and manufacture of hydro turbine models at Uralenergoresurs OOO (in Magnitogorsk) for recovery of energy of water drainage 
and backfilling systems contaminated hydro mixtures in underground mine conditions (Fig. 2).

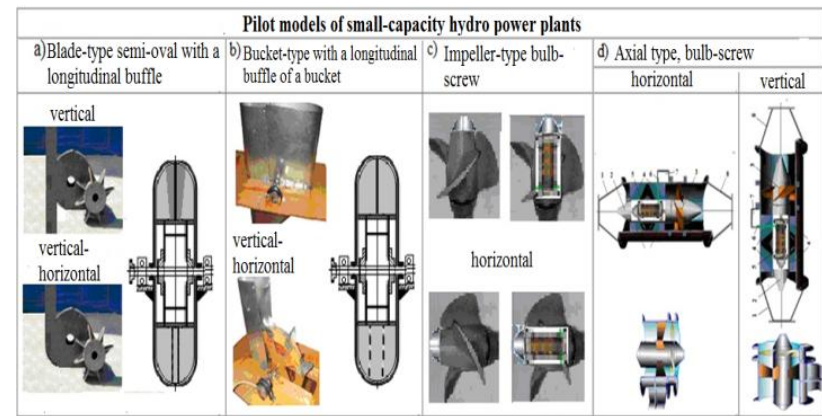

Fig. 2. Hydro turbine design approved for pilot-scale tests

With due account for constant input and variable design parameters of the mining engineering system the parameter characteristics of mixture feeding to a turbine have been calculated to provide the highest efficiency and minimized wear of the hydro turbine for the HPP being designed: height of a mixture single-stage transfer - 30-100 m; angle of mixture falling on a turbine - 65900 .

Design calculations and full-scale experiments have proved in practice that in underground mine conditions application of the electric energy regeneration system based on mine water flows of a water drainage system and hydraulic flows of backfilling mixtures on the basis of thickened ore dressing tailings on upper and lower horizons of underground mines of the Urals provides a $20 \%$ decrease of mine electricity consumption and in general enhances energy efficiency of mineral deposit development.

Irregular loading of mine transport machinery at different sections of a mine, repair, maintenance and other auxiliary processes can also be viewed as reserves of the air flow residual energy application for the formation of renewable sources of electricity. A schematic circuit diagram of electricity generation due to the air flow residual energy with the use of smallcapacity generators is shown in Fig. 3.

In underground mine conditions, the downward force of heavy machinery, recuperation of brake energy of lifting and transport equipment are additional sources of renewable energy. Recuperation systems have got widespread use throughout the world. In this area work is under way in some of the known Russian companies using recuperation systems with stationary hoist and winder installations (for instance, Kazsk Branch of Evrazruda OAO, Primorsky GOK, Vorkutaugol OAO, Osinnikovskaya Mine of Yuzhkuzbassugol OAO).

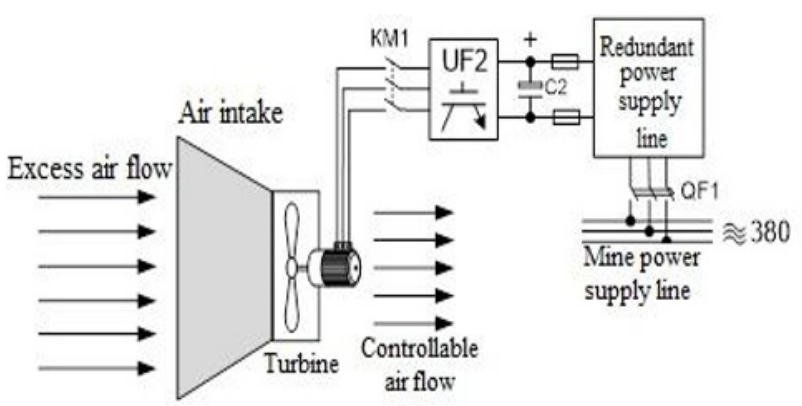

Fig. 3. Generator schematic circuit diagram for electricity generation based on the air flow residual energy as a renewable energy source.

Solutions have been developed for some conditions of cage hoist operation providing energy generation both for man and material roundtrip running, and for electricity return to the mine power supply line with its eventual use for other purposes. Energy saving is estimated at up to $75 \%$ as compared to conventional two-speed hoists.

Besides, rather promising is the conversion of heavy machinery downward force energy into electric power. For this purpose in mine transport operational stop points (discharge point, ore or rock passes, weighing point, drift entry, etc.) specially-designed gyro-platforms can be installed. Heavy transport machinery downward force energy is converted into electricity with the use of systems transferring power fluid mechanical energy to mechanical energy and then to electric power, or, in case of ferromagnetic fluid, immediately to electric power.

Another challenging process solution, particularly for deeply occurring mineral deposit development with the application of hot air systems, is the use of water in air cooling systems. Air-heated mine water is used in hydro lift systems for pressure handling of mined material to the surface. Formation of a common hydro network in a mine provides comprehensive minimization of ventilation and mine water drainage costs, as well as mined material transportation costs.

Cutting of natural sources energy consumption and involvement of technology-related renewable energy sources in mining are also realizable due to technological advancement. Energy of virgin rock failure under the force of gravity; energy of rock mass straining under rock pressure forces; energy of heat exchange processes in virgin rock caused by endogenous processes of drillhole and shaft in-situ leaching, geothermal energy and technology-related thermal energy resulting from the implementation of physical and chemical geotechnologies are also the areas of research into technology-related renewable energy sources, formed in the course of geotechnology processes.

For the creation of energy-efficient geotechnologies at the final stage of gold deposit development it is necessary to implement the following system of measures:

a) assessment of energy potential of mine flows transferred in the course of implementation of gold-ore underground mining processes, namely: hydraulic 
mixtures, mine air flows, downward force of heavy machinery, temperature gradient of the environment; b) process audit and systematization of opportunities of the enhancement of process efficiency based of novel geotechnology application for the formation and use of renewable energy sources;

c) understanding of the objective laws governing the influence of geological and mining factors on energy efficiency of geotechnology processes;

d) elaboration of methods and procedures for grounding of the parameters of main, auxiliary and return mine flows to enhance energy efficiency of the application of geotechnology process energy potential;

e) elaboration of methods and procedures to provide the design rationale of the parameters of energy-efficient mining engineering systems with a full cycle of comprehensive mineral deposit development.

\section{Conclusions}

Tests and trials of the performed design and engineering solutions at mines of YuGK AO based on the results of the performed studies for the preparation of the rationale of the new concept and geotechnology of vein gold deposit development at the final stage have proved conclusively that for the finalizing of the development of non-placer gold deposit on-balance (economically mineable) reserves the multifaceted nature, multifunctionality and non-depletability of underground mineral resources determine the opportunity of multistage and long-term use of these diverse resources and properties.

In-mine consumption of electricity regenerated in the processes of gold deposit development based on technology-related renewable energy sources and exploring new non-conventional electrical and mechanical aids is one of the areas of ore mining energy efficiency growth at gold mines.

The studies are performed with the support of the Russian Science Foundation (Project No14-37-00050)

\section{References}

1. K.N. Trubetskoi, Yu.P. Galchenko, Geoecology of subsoil development and ecogeotechnology of mineral resources exploitation. Publishing house "Nauchtekhlitizdat", 360 (2015)

2. I.A. Tangayev, Energy intensity of minerals mining and processing. Nedra, 231 (1986)

3. V.I. Golik, S.V. Leonov, E.V. Shevchenko, Nature management rationalization in the strategy of industrial enterprises development: an academic project. Culture, 380 (2012)

4. K.K. Ilkovsky, D.I. Timofeev, Mining Journal, 11, 73-73 (2011)

5. A. McIvor, Cleantech, 5, 16-19 (2010)

6. K.N. Trubetskoy, D.R. Kaplunov, M.V. Ryl'nikova, D.N. Radchenko, Journal of mining science, 3, 5866 (2011), DOI: 10.1134/S1062739147030087
7. D.R. Kaplunov, D.N. Radchenko, Mining Information and Analytical Bulletin (Scientific and Technical Journal), 1, 447-455 (2011)

8. V.N. Kalmykov, M.V. Rylnikova, O.V. Petrova, T.P. Plesovskikh, The "Mine Surveying Bulletin" magazine, 1, 59-64 (2012)

9. K.I. Strukov, Gornyi Zhurnal (Mining Journal), 9, 21-25 (2017), DOI: 10.17580/gzh.2017.09.04.

10. K.I. Strukov, M.V. Rylnikova, I.L. Nikiforova, Mining Industry Journal, 2, 46-49 (2018), №2, DOI: 10.30686/1609-9192-2018-2-138-46-48

11. K.I. Strukov, R.V. Berger, V.V. Fedoseev, M.V. Rylnikova, Gornyi Zhurnal (Mining Journal), 6, 5-8 (2017), DOI: 10.17580/gzh.2017.06.01

12. M.V. Rylnikova, V.A. Ezhov, I.L. Nikiforova, S.N. Plotnikov, Gornyi Zhurnal (Mining Journal), 9, 3540 (2017), DOI: 10.17580/gzh.2017.09.07

13. D.R. Kaplunov, M.V. Rylnikova, Gornyi Zhurnal (Mining Journal), 9, 72-75 (2015), DOI: 10.17580/gzh.2015.09.16

14. D.R. Kaplunov, S.G. Leizerovich, V.K. Tomaev, Gornyi zhurnal (Mining Journal), 4, 62-66 (2013)

15. M.V. Rylnikova, K.I. Strukov, V.V. Olizarenko, I.S. Turkin, Gornyi Zhurnal (Mining Journal), 11, 71-76 (2017), DOI: 10.17580/gzh.2017.11.13 